\title{
Phenolic compounds from Achillea millefolium L. and their bioactivity
}

\author{
Sara Vitalini ${ }^{1,7}$, Giangiacomo Beretta², Marcello Iriti ${ }^{\square}$, Simone Orsenigo ${ }^{3}$, Nicoletta Basilico ${ }^{4}$, \\ Stefano Dall'Acqua ${ }^{5}$, Maria lorizzi ${ }^{6}$ and Gelsomina Fico ${ }^{3,7}$
}

'Dipartimento di Produzione Vegetale, 2Dipartimento di Scienze Farmaceutiche "Pietro Pratesi", 3Dipartimento di Biologia, "4Dipartimento di Sanità Pubblica - Microbiologia - Virologia, Università degli Studi di Milano, Milano, Italy; ${ }^{5}$ Dipartimento di Scienze Farmaceutiche, Università degli Studi di Padova, Padova, Italy; 'Dipartimento di Scienze e Tecnologie per l'Ambiente e il Territorio, Università degli Studi del Molise, Pesche (Isernia), Italy; 'Orto Botanico 'G. E. Ghirardi', Dipartimento di Biologia, Università degli Studi di Milano, Toscolano Maderno (Brescia), Italy

\begin{abstract}
Since antiquity, Achillea millefolium L. (Asteraceae) has been used in traditional medicine of several cultures, from Europe to Asia. Its richness in bioactive compounds contributes to a wide range of medicinal properties. In this study, we assessed $A$. millefolium methanolic extract and its isolated components for free radical scavenging activity against 2,2-diphenyl-pycrilhydrazyl, total antioxidant capacity (based on the reduction of $\mathrm{Cu}^{++}$to $\left.\mathrm{Cu}^{+}\right)$, and ability to inhibit lipid peroxidation. The activity against chloroquine-sensitive and chloroquine-resistant strains of Plasmodium falciparum was also tested. Chlorogenic acid, its derivatives and some flavonoids isolated by semipreparative HPLC and identified by NMR and spectrometric techniques were the major bioactive constituents of the methanolic extract. The latter exhibited significant antioxidant properties, as well as its flavonol glycosides and chlorogenic acids. With regard to the antiplasmodial activity, apigenin 7-glucoside was the most effective compound, followed by luteolin 7-glucoside, whereas chlorogenic acids were completely inactive. On the whole, our results confirmed $A$. millefolium as an important source of bioactive metabolites, justifying its pharmaceutical and ethnobotanical use.
\end{abstract}

Keywords: Achillea millefolium, Asteraceae, dicaffeoylquinic acids, flavonol glycosides, antioxidant power, antiplasmodial activity

Received: 21 October, 2010; revised: 24 January, 2011; accepted: 08 March, 2011; available on-line: 19 April, 2011

\section{INTRODUCTION}

Achillea millefolium L. (Asteraceae) grows wild all around Europe, Asia, North Africa and North America and it is widely used in Italian folk medicine (Pieroni \& Quave, 2005; Passalacqua et al., 2007; Vitalini et al., 2009). Its properties have been known since antiquity and its use is diffused in many cultures from Europe to Asia: in Greece, in the region of Thessaloniki, for instance, A. millefolium is recommended for the treatment of many different ailments (Kokkini et al., 2004); in West Azerbaijan, Iran, the infusion of dried flowers is considered suitable for the treatment of hemorrhoids, dyspepsia, dysmenorrhoea and gastritis (Miraldi et al., 2001); in the Parvati valley, west Himalaya, India, leaves and flowers are used for gastric problems and fever (Sharma et al., 2004).

Since 1975, several studies on the phytochemical composition of $A$. millefolium have been reported and led to the identification of flavonoids and caffeic acid derivatives (Falk et al., 1975; Guédon et al., 1993; Glasl et al., 2002; Benedek et al., 2007; Innocenti et al., 2007). All these studies increased the knowledge on the chemical composition of this species but, to date, a complete characteristicts of its phenolic compounds is not yet available.

Concerning the bioactivity of this plant, recent studies reported antimicrobial, antiphlogistic, hepatoprotective, antispasmodic and calcium antagonist activities of its polar extracts (Stojanović et al., 2005; Yaeesh et al., 2006), and a protective effect of its infusions against $\mathrm{H}_{2} \mathrm{O}_{2}$ induced oxidative damage in human erythrocytes and leucocytes (Konyalioglu \& Karamenderes, 2005). Some articles have described antimalarial activity of flavonoids from plant sources (Schwikkard \& van Heerden, 2002; Saxena et al., 2003; Lehane \& Saliba, 2008; Kaur et al., 2009) and, particularly, Murnigsih and colleagues (2005) screened the activity of water extract of $A$. millefolium against Plasmodium falciparum with positive results, stimulating our interest to study the activity of methanolic extract from $A$. millefolium and of its pure compounds.

Hence, the first aim of the present work was to achieve a comprehensive characterization of phenolic bioactive compounds present in this species; subsequently, the crude extract and pure compounds were tested in different models for antioxidant and antiplasmodial activities.

\section{MATERIALS AND METHODS}

Chemicals. Ascorbic acid (99\%), chlorogenic acid $(95 \%)$, gallic acid $(98 \%)$ and quercetin $(98 \%)$ were from Sigma-Aldrich (Milan, Italy). The organic solvents were all of analytical grade (Sigma-Aldrich, Milan, Italy). Deuterated dimethylsulphoxide $\left(\mathrm{dmso-}^{6}\right)$ was from SigmaAldrich (Milan, Italy).

\footnotetext{
e-mail: marcello.iriti@unimi.it

Abbreviations: CQ, chloroquine; DCQA, dicaffeoyl-quinic acid; DPPH, 2,2-diphenyl-picrylhydrazyl; ESI-MS/MS, electrospray ionization tandem mass spectrometry; HPLC, high performance liquid chromatography; $I C_{50}, 50 \%$ inhibitory concentration; LDL, low density lipoproteins; $m$, molecular mass; NMR, nuclear magnetic resonance; $P B S$, phosphate buffered saline; $R P$, reverse phase; $R_{t}$ retention time; S.D., standard deviation; TAC, total antioxidant capacity; TBARS, thiobarbituric acid-reactive substance; TLC, thin layer chromatography; TMS, tetramethylsilane; $t_{R}$, relative retention time
} 
Plant material. The aerial parts of $A$. millefolium were collected during summer 2007, in Oro di Morondo, Varallo Sesia $(700 \mathrm{~m})$ (Vercelli, Italy). A voucher specimen (no. Am 310) has been deposited in the Department of Biology of Milan University after their identification by an expert local botanist (Dr. Gianfranco Rotti), according to "Flora d'Italia" (Pignatti, 1982).

Extraction, isolation and identification. Air-dried, powdered aerial parts of $A$. millefolium (112 g) were extracted exhaustively with $n$-hexane, $\mathrm{CHCl}_{3}, \mathrm{CHCl}_{3} /$ $\mathrm{MeOH}(9: 1, \mathrm{v} / \mathrm{v})$ and $\mathrm{MeOH}$ in a Soxhlet apparatus. $\mathrm{MeOH}$ extract $(4.5 \mathrm{~g})$ was chromatographed on Sephadex LH-20 (Pharmacia, $100 \times 2.5 \mathrm{~cm}$, flow rate $3.0 \mathrm{~mL} /$ min) using $\mathrm{MeOH}$ as eluent, giving 254 fractions of 3 $\mathrm{mL}$, combined together into 20 subfractions according to TLC separations (Silica $60 \mathrm{~F}_{254}$-gel coated aluminium sheets; eluent: $n$ - $\mathrm{BuOH} / \mathrm{CH}_{3} \mathrm{COOH} / \mathrm{H}_{2} \mathrm{O}$ (60:15:25, by vol.)).

Subfractions 4-5, 6-7 and 10-11 were further combined together, according to their chromatographic (TLC) chemical pattern, and submitted to RP-HPLC on $\mathrm{C}_{18} \mu$-Bondapak column $(300 \mathrm{~mm} \times 7.8 \mathrm{~mm}$, flow rate $2.5 \mathrm{~mL} / \mathrm{min})$ with $\mathrm{MeOH} / \mathrm{H}_{2} \mathrm{O}(40: 60, \mathrm{v} / \mathrm{v})$ to yield compounds 1 (5 mg) ( $\left.t_{\mathrm{R}}=8.27 \mathrm{~min}\right), 2(4 \mathrm{mg})\left(t_{\mathrm{R}}=23.17\right.$ $\mathrm{min}), \mathbf{3}, \mathbf{5}, \mathbf{6}, 7$ and $\mathbf{8}(3.5 \mathrm{mg})\left(t_{\mathrm{R}}=29.24 \mathrm{~min}\right)$. The purity of all substances was between 95 and $98 \%$ based on ${ }^{1} \mathrm{H}$ NMR and HPLC analysis. Compound 4 was identified by comparison with a sample previously isolated (Innocenti et al., 2007).

${ }^{1} \mathrm{H}$ NMR spectra were recorded at $303 \mathrm{~K}$ in Fourier transform mode at $300 \mathrm{MHz}$ on a Varian Mercury VX instrument (Varian, Torino, Italy) equipped with a broad band $20-\mathrm{mm}$ probe, using a spectral width of 20 p.p.m. and TMS as internal standard. HPLC-ESI-MS analysis was performed with a Thermo Finnigan LCQ Advantage ion trap mass spectrometer (Thermoquest, Milan, Italy). The ESI/MS source was set as follows: capillary temperature $220^{\circ} \mathrm{C}$; spray voltage $4.5 \mathrm{kV}$; capillary voltage $10 \mathrm{~V}$ (positive ion mode) or -3 (negative ion mode); sheath gas flow rate $2 \mathrm{~L} / \mathrm{min}$; auxiliary gas flow rate $5 \mathrm{~L} / \mathrm{min}$. Spectra were detected in positive and negative ion mode (100$1000 \mathrm{~m} / \mathrm{z}, 0.5 \mathrm{scan} / \mathrm{s})$. Components were separated on a Phenomenex Synergy RP80 A column $(150 \mathrm{~mm} \times 2 \mathrm{~mm}$ i.d., particle size $4 \mu \mathrm{m})$ protected with a Max-RP guard column $(4 \mathrm{~mm} \times 2 \mathrm{~mm}$ i.d., particle size $4 \mu \mathrm{m})$. Gradient elution: $100 \%$ solvent $\mathrm{A}\left(\mathrm{H}_{2} \mathrm{O}, 0.1 \% \mathrm{HCOOH}\right)$ to $60 \%$ $\mathrm{B}\left(\mathrm{CH}_{3} \mathrm{CN}, 0.1 \% \mathrm{HCOOH}\right)$ in $60 \mathrm{~min}$, followed by reequilibration. Flow rate $0.2 \mathrm{~mL} / \mathrm{min}$.

Parasite cultures and drug susceptibility assay. P. falciparum cultures were carried out according to Trager and Jensen (1976) with minor modifications. Briefly, the CQsensitive (D10) and CQ-resistant (W2) strains were maintained at 5\% hematocrit (human type A-positive red blood cells) in RPMI 1640 (EuroClone, Celbio) medium with the addition of $1 \%$ AlbuMaxII (lipid-rich bovine serum albu$\mathrm{min}$ ), $0.01 \%$ hypoxantine, $20 \mathrm{mM}$ Hepes, $2 \mathrm{mM}$ glutamine. All the cultures were maintained at $37^{\circ} \mathrm{C}$ in a standard gas mixture consisting of $1 \% \mathrm{O}_{2}, 5 \% \mathrm{CO}_{2}, 94 \% \mathrm{~N}_{2}$. Compounds were dissolved in either $\mathrm{H}_{2} \mathrm{O}$ or $\mathrm{EtOH}$ and then diluted with medium to achieve the required concentrations (final EtOH concentration $<1 \%$, which is non-toxic to the parasite). Samples were placed in 96-well flat-bottom microplates (COSTAR) after serial dilutions. Asynchronous cultures with parasitaemia of $1-1.5 \%$ and $1 \%$ final hematocrit were aliquoted into the plates and incubated at $37^{\circ} \mathrm{C}$ for 72 h. Parasite growth was determined spectrophotometrically $\left(\mathrm{OD}_{650}\right)$ by measuring the activity of the parasite lactate dehydrogenase $(\mathrm{pLDH})$, according to a modified version of the method of Makler et al. (1993), in control and treated cultures. The antimalarial activity is expressed as $\mathrm{IC}_{50}$; each $\mathrm{IC}_{50}$ value is the mean \pm S.D. of at least three separate experiments performed in duplicate.

Determination of polyphenolic content. Total polyphenols were quantified colorimetrically by the Folin-Ciocalteau assay using gallic acid as reference standard (Vitalini et al., 2006). An aliquot of the samples was combined with $50 \mu \mathrm{L}$ of Folin-Ciocalteau reagent; after $3 \mathrm{~min}, 100 \mu \mathrm{L}$ of a saturated sodium carbonate solution was added and then distilled water to reach a final volume of $2.5 \mathrm{~mL}$. After $1 \mathrm{~h}$ of incubation in the dark at room temperature, the absorbance was read at $725 \mathrm{~nm}$. Results were reported as $\mathrm{mEq}$ gallic acid.

DPPH scavenging test. The DPPH assay was performed as previously described (Vitalini et al., 2006). Briefly, aliquots of the $\mathrm{MeOH}$ extract and pure compounds, at five different concentrations (from 1 to 100 $\mu \mathrm{M})$, were added to a $15 \mu \mathrm{M}$ EtOH solution of DPPH free radical. Absorbance at $517 \mathrm{~nm}$ was read after 15 min of incubation in the dark. The $\mathrm{IC}_{50}$ was calculated with Prism ${ }^{\circledR} 4$ (GraphPad Software Inc.). Each $\mathrm{IC}_{50}$ value is the mean \pm S.D. of at least three separate experiments performed in duplicate.

Total antioxidant capacity. Total antioxidant capacity (TAC) of the samples (at two concentrations: 1 and $10 \mu \mathrm{M}$ ) was measured by a validated assay based on copper (II) reduction. (BIOXYTECH ${ }^{\circledR}$ AOP-490TM, Oxis Research ${ }^{\mathrm{TM}}$, Portland, OR, USA) (Vitalini et al., 2006). Results were reported as $\mathrm{mEq}$ uric acid.

Lipid peroxidation measurement. The lipid peroxidation analysis was carried out according to a procedure previously reported (Vitalini et al., 2006). After isolation of human LDL by sequential ultracentrifugation, the total protein content was determined by the Bradford method. Subsequently, LDL fraction was diluted to 200 $\mu \mathrm{g}$ protein/mL in $10 \mathrm{mM}$ PBS. The content of TBARS was employed as a measure of lipid peroxidation. LDL fraction $(500 \mu \mathrm{L})$, containing $100 \mu \mathrm{g}$ of lipoprotein was treated by the addition of $\mathrm{MeOH}$ extract or pure compounds at concentrations of $10 \mu \mathrm{M}$ or $1 \mu \mathrm{M}$ and then incubated for $15 \mathrm{~min}$ at $37^{\circ} \mathrm{C}$. Oxidation was triggered by the addition of $\mathrm{CuSO}_{4}(5 \mu \mathrm{M})$ and samples were incubated at $37^{\circ} \mathrm{C}$ for $3 \mathrm{~h}$. Then, $300 \mu \mathrm{L}$ of each sample was assayed by the addition of $600 \mu \mathrm{L}$ of thiobarbituric acid reagent $(0.375 \mathrm{~g}$ thiobarbituric acid, $2.08 \mathrm{~mL} 12 \mathrm{M}$ $\mathrm{HCl}, 15 \mathrm{~mL}$ trichloroacetic acid 100\% and distilled water to a final volume of $100 \mathrm{~mL}$ ) and boiled for $15 \mathrm{~min}$. After centrifugation $\left(10000 \times g\right.$ for $10 \mathrm{~min}$ at $\left.4^{\circ} \mathrm{C}\right)$, supernatants were analysed spectrophotometrically at $532 \mathrm{~nm}$. Results are expressed as nmol of TBARS/mg of LDL protein.

Statistical analyses. Results are expressed as mean \pm S.D. of three independent determinations. All statistical analyses were performed using the SPSS ver. 17.0 software for Windows (SPSS, Chicago, IL, USA). Relationships between variables were examined by Spearman rank nonparametric correlation analysis. Multivariable linear regression was used to identify variables that influence the antiplasmodial activity, and conducted using a stepwise algorithm.

\section{RESULTS AND DISCUSSION}

\section{Phytochemical study}

Table 1 shows chemical structures of ten compounds identified in the $\mathrm{MeOH}$ extract of the aerial parts of 
Table 1. Compounds identified in methanol extract of $A$. millefolium $\mathrm{L}$.

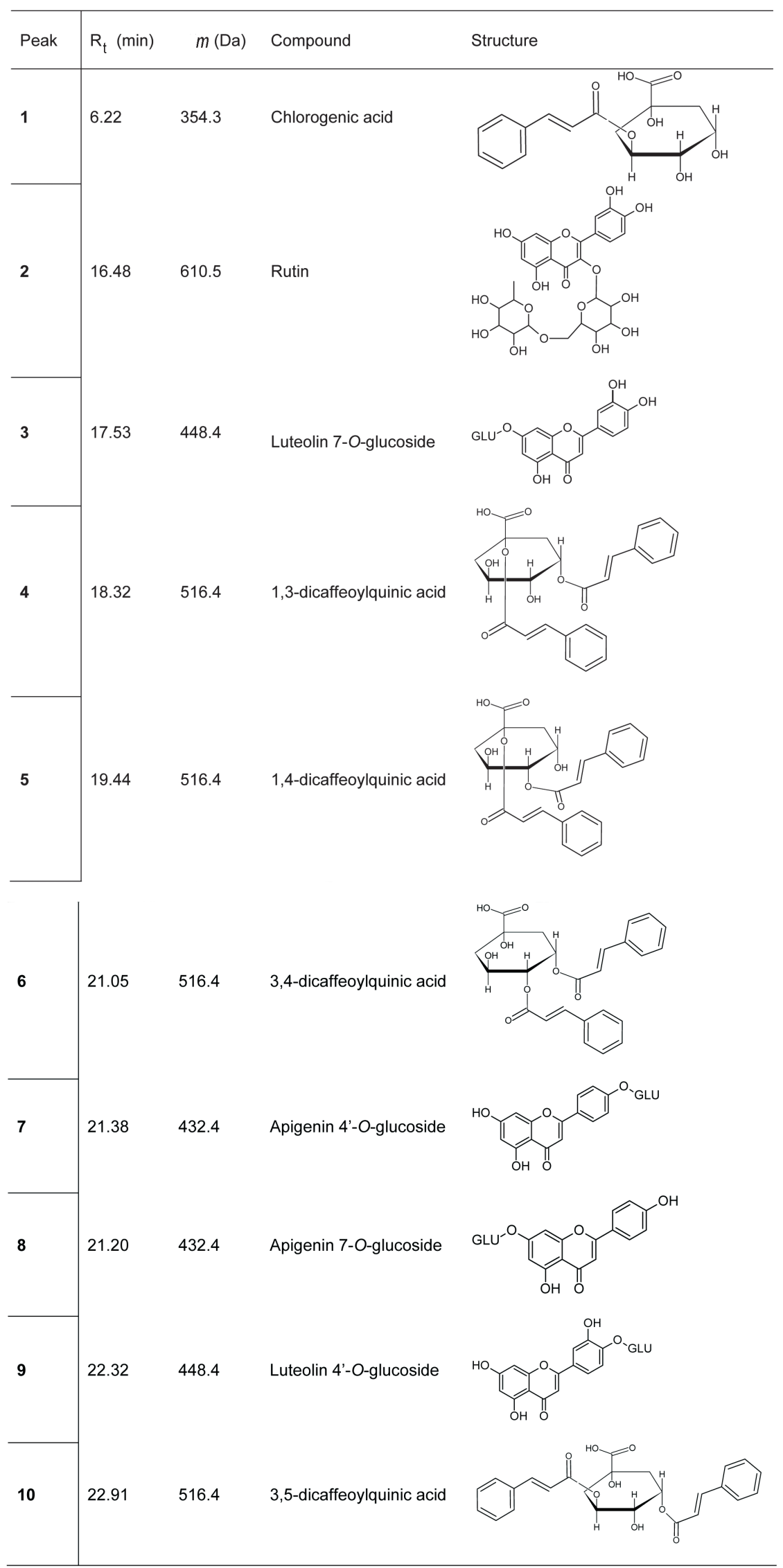




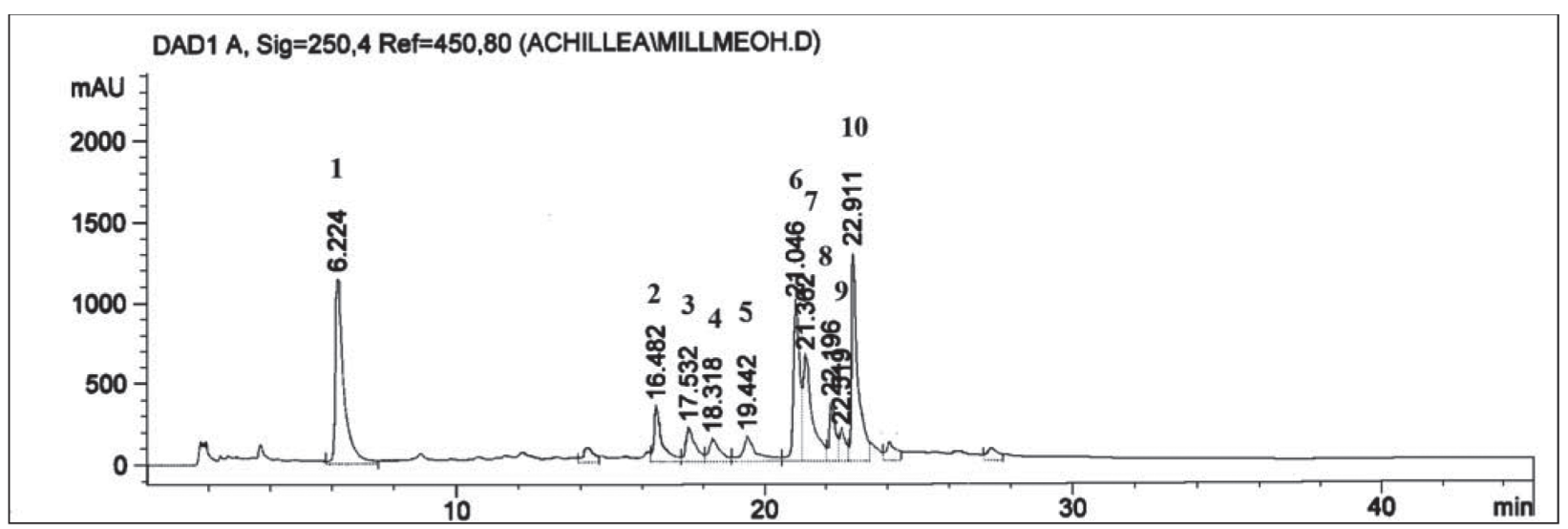

Figure 1. HPLC profile $(\lambda=250 \mathrm{~nm})$ of methanolic extract from $A$. millefolium

1, Chlorogenic acid; 2, rutin; 3, luteolin 7-O-glucoside; 4, 1,3-dicaffeoylquinic acid; 5, 1,4-dicaffeoylquinic acid; 6, 3,4-dicaffeoylquinic acid; 7, apigenin 4'-O-glucoside; 8 , apigenin 7-O-glucoside; $\mathbf{9}$, luteolin 4'-O-glucoside; 10, 3,5-dicaffeoylquinic acid.

A. millefolium. These compounds accounted for over $90 \%$ of the total area of the HPLC chromatogram $(\lambda=250 \mathrm{~nm})$. Three major peaks, detected at $\mathrm{R}_{\mathrm{t}}=6.22$ $\min , R_{t}=21.05 \mathrm{~min}$ and $R_{t}=22.91 \mathrm{~min}(\mathbf{1}, \mathbf{6}$ and 10 respectively) and two minor peaks detected at $R_{t}=18.32$ min and at $R_{t}=19.44$ min (4 and 5) were tentatively attributed to five caffeic acid derivatives, whereas minor peaks 2, 3, 7, 8 and 9 were identified as flavonoid glycosides on the basis of their UV spectra (not shown).

In accordance with the results from previous studies (Benedek et al., 2007; Innocenti et al., 2007), compounds $1,2,3,8$ and 9 were identified as chlorogenic acid, rutin, luteolin 7-O-glucoside, apigenin 7-O-glucoside, and luteolin 4'-O-glucoside, by comparison of their chromatographic retention times and spectral data with those of pure commercially available compounds.

The peaks corresponding to compounds $\mathbf{6}, \mathbf{7}$, and $\mathbf{1 0}$ were isolated by semi-preparative HPLC and identified by NMR and HPLC-MS techniques.
The HPLC-DAD chromatogram $(\lambda=250 \mathrm{~nm}$, Fig. 1) showed the presence of two main peaks $\left(R_{t}=21.04\right.$ min and $\mathrm{R}_{\mathrm{t}}=21.36 \mathrm{~min}$ ) corresponding to compounds 6 and 10 characterized by identical UV spectra, with two main peaks at $\lambda_{\max } 217 \mathrm{~nm}$ and $329 \mathrm{~nm}$ and shoulders at $239 \mathrm{~nm}$ and $300 \mathrm{~nm}$ (not shown), typical of the chlorogenic acid chromophore. The presence of two chlorogenic acid moieties in these compounds was confirmed by the HPLC-ESI-MS experiments that evidenced, in all cases, protonated pseudo-molecular ions at $\mathrm{m} /$ ₹ 517 $\left[\mathrm{M}+\mathrm{H}^{+}\right](m 516 \mathrm{Da})$. The presence of a fragment ion at $m / z .355[\mathrm{M} \text {-caffeoyl }+\mathrm{H}]^{+}$, in the ESI-MS ${ }^{2}$ spectra of both compounds (not shown) indicated the structure of two isomeric dicaffeoyl derivatives of quinic acid never reported before in $A$. millefolium. Unequivocal confirmation of these structures was achieved by ${ }^{1} \mathrm{H}$ NMR analyses. In accordance with the NMR data previously reported (Wang \& Liu, 2007), these two major isomeric species were identified as 3,4-DCQA (compound 6) and 3,5-DCQA (compound 10).

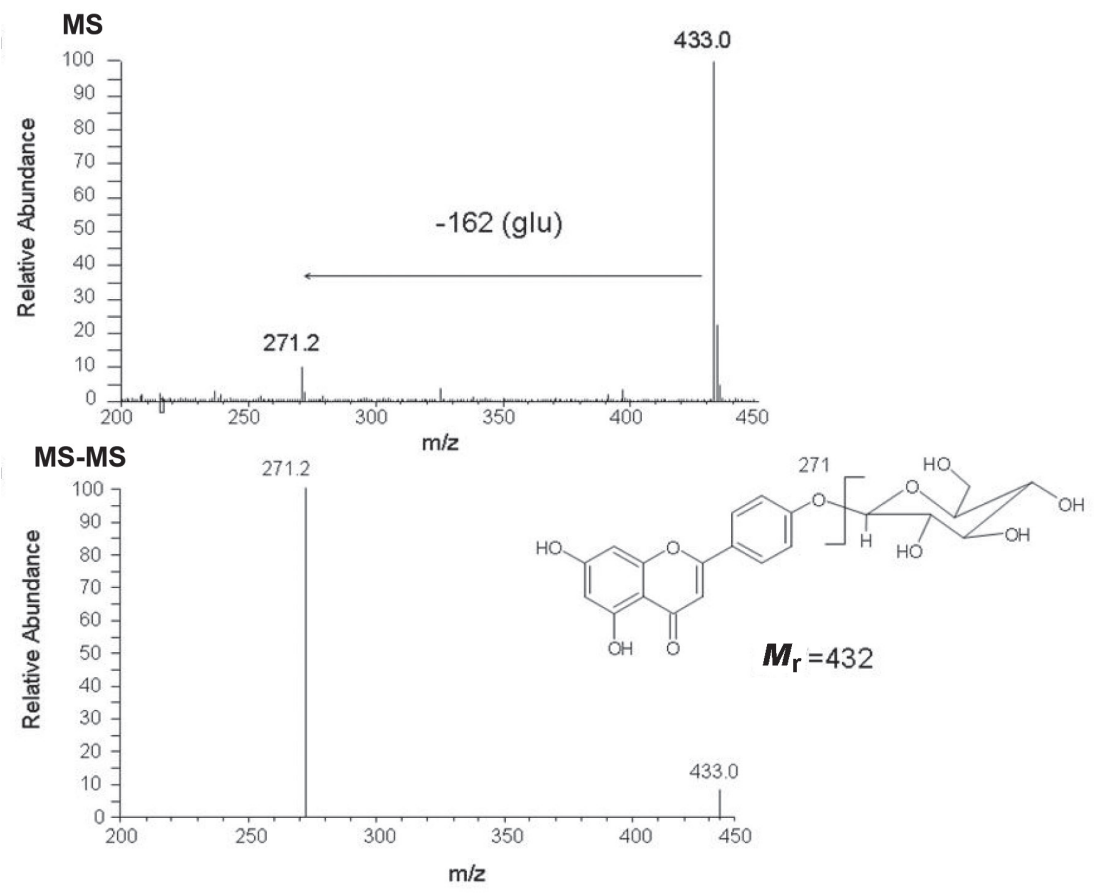

Figure 2. HPLC-ESI-MS and HPLC-ESI$M S^{2}$ spectra of pseudo-molecular ion of compound 7 at $[\mathrm{M}+\mathrm{H}]^{+} \mathrm{m} / \mathrm{z} 433$ 
Table 2. In vitro antiplasmodial activity against D10 and W2 strains of $P$. falciparum

\begin{tabular}{|c|c|c|}
\hline Compound & $\begin{array}{l}\text { D10 } \\
\mathrm{IC}_{50}(\mu \mathrm{g} / \mathrm{mL})\end{array}$ & $\begin{array}{l}\text { W2 } \\
\mathrm{IC}_{50}(\mu \mathrm{g} / \mathrm{mL})\end{array}$ \\
\hline Chloroquine & $0.010 \pm 0.03$ & $0.18 \pm 0.07$ \\
\hline Luteolin & $6.1 \pm 0.8$ & $5.0 \pm 1.1$ \\
\hline Apigenin & $25.4 \pm 7.9$ & $20.2 \pm 6.4$ \\
\hline 1 & $>100$ & $>100$ \\
\hline 2 & $68.5 \pm 22.9$ & $76.4 \pm 7.7$ \\
\hline 3 & $26.2 \pm 13.5$ & $26.8 \pm 3.6$ \\
\hline \multicolumn{3}{|l|}{4} \\
\hline \multicolumn{3}{|l|}{5} \\
\hline \multicolumn{3}{|l|}{6} \\
\hline \multicolumn{3}{|l|}{10} \\
\hline 7 & $71.4 \pm 11$ & $58.7 \pm 11.2$ \\
\hline 8 & $10.1 \pm 1.3$ & $6.1 \pm 3.8$ \\
\hline 9 & $>100$ & $>100$ \\
\hline Methanolic extract & $>100$ & $44.6 \pm 8.8$ \\
\hline
\end{tabular}

aCompounds 4-6 and $\mathbf{1 0}$ in the same fraction tested before their identification. The results are expressed as $I C_{50} \pm$ S.D. of three different experiments each performed in duplicate.
The identity of compound 7 was established on the basis of (i) its protonated $[\mathrm{M}+\mathrm{H}]^{+}$pseudo-molecular ion at $m / z 433$ and of a fragment at $m / z 271$ in the ESI-MS/MS spectrum (Fig. 2), and of (ii) its ${ }^{1} \mathrm{H}$ and ${ }^{13} \mathrm{C}$ NMR data $\left(\right.$ dmso- $\left._{6}, 300 \mathrm{MHz}\right)$ that, according to the ${ }^{1} \mathrm{H}$ NMR data reported by Teng and colleagues (2002), were consistent with the structure of apigenin $4^{\prime}-O-\alpha-$ glucopyranoside 7 , an unusual derivative of apigenin, identified in this study for the first time in A. millefolium.

The results of this part of the work have demonstrated that the phytochemical profile of $A$. millefolium is mainly characterized by the presence of chlorogenic acid and its caffeoilquinic derivatives, besides luteolin, rutin, and apigenin flavonoid glycosides, some of which never reported before in this important plant species.

\section{Antiplasmodial activity}

The crude $\mathrm{MeOH}$ extract and its isolated components were tested for antiplasmodial activity in CQ-sensitive (D10) and CQ-resistant (W2) strains of P. falciparum, using CQ as a positive control. The results (Table 2) showed that the crude $\mathrm{MeOH}$ extract did not induce $50 \%$ mortality in the D10 strain of the parasite even at the highest concentration tested, but showed a measurable activity against the CQ-resistant W2 strain, with an $\mathrm{IC}_{50}$ value of $44.6( \pm 8.8) \mu \mathrm{g} / \mathrm{mL}$.

Among the isolated compounds, apigenin 7-O-glucoside (8) and luteolin 7-O-glucoside (3) were the most active against both strains of $P$. falciparum (Table 2), in accordance with the findings from a previous study, in which both luteolin and apigenin inhibited the growth of other strains (3D7 and 7G8) of P. falciparum (Lehane

Table 3. Antioxidant activity of methanolic extract from A. millefolium and its isolated pure constituents in different model systems

\begin{tabular}{|c|c|c|c|c|c|}
\hline \multirow[t]{2}{*}{ Samples } & \multirow{2}{*}{$\frac{\operatorname{DPPH}\left(\mathrm{IC}_{50}\right)^{\mathrm{a}}}{1 \mu \mathrm{M}}$} & \multicolumn{2}{|c|}{$\begin{array}{l}\text { Antioxidant capacity } \\
\text { (mEq uric acid) }{ }^{b}\end{array}$} & \multicolumn{2}{|c|}{$\begin{array}{l}\text { TBARS } \\
(\mathrm{nmol} \text { TBARS/mg LDL)c }\end{array}$} \\
\hline & & $1 \mu \mathrm{M}$ & $10 \mu \mathrm{M}$ & $1 \mu \mathrm{M}$ & $10 \mu \mathrm{M}$ \\
\hline Ascorbic acid & $1.31 \pm 0.12$ & $0.33 \pm 0.02$ & $0.36 \pm 0.02$ & $70.00 \pm 2.10$ & $4.62 \pm 0.54$ \\
\hline Chlorogenic acid & $5.70 \pm 0.24$ & $0.41 \pm 0.06$ & $1.48 \pm 0.15$ & $11.03 \pm 0.77$ & $3.52 \pm 0.49$ \\
\hline Quercetin & $4.37 \pm 0.21$ & $0.75 \pm 0.06$ & $2.17 \pm 0.17$ & $3.85 \pm 0.50$ & $0.75 \pm 0.04$ \\
\hline 1 & $1.58 \pm 0.11$ & $0.30 \pm 0.05$ & $1.40 \pm 0.38$ & $71.49 \pm 1.44$ & $4.47 \pm 0.62$ \\
\hline 2 & $1.50 \pm 0.11$ & $0.35 \pm 0.07$ & $1.84 \pm 0.47$ & $70.54 \pm 1.09$ & $4.94 \pm 0.71$ \\
\hline 3 & $1.10 \pm 0.09$ & $0.11 \pm 0.03$ & $1.61 \pm 0.52$ & $10.04 \pm 0.55$ & $4.27 \pm 0.46$ \\
\hline \multicolumn{6}{|l|}{4} \\
\hline \multicolumn{6}{|l|}{5} \\
\hline 6 & $3.78 \pm 0.33^{d}$ & $0.34 \pm 0.04^{d}$ & $1.56 \pm 0.63^{d}$ & $69.59 \pm 1.12^{d}$ & $3.04 \pm 0.39^{d}$ \\
\hline \multicolumn{6}{|l|}{10} \\
\hline 7 & $3.83 \pm 0.46$ & $0.39 \pm 0.05$ & $1.72 \pm 0.56$ & $64.00 \pm 0.96$ & $3.66 \pm 0.40$ \\
\hline 8 & $2.70 \pm 0.17$ & $0.21 \pm 0.03$ & $1.08 \pm 0.34$ & $10.79 \pm 0.48$ & $4.27 \pm 0.62$ \\
\hline 9 & $2.68 \pm 0.13$ & $0.09 \pm 0.01$ & $0.20 \pm 0.06$ & $72.11 \pm 1.56$ & $12.84 \pm 0.99$ \\
\hline $\mathrm{MeOH}$ extract e & $1.18 \pm 0.10$ & $0.17 \pm 0.05$ & $1.07 \pm 0.29$ & $50.40 \pm 1.79$ & $2.47 \pm 0.51$ \\
\hline
\end{tabular}

$\mathrm{alC}_{50}=$ concentration of sample needed to achieve $50 \%$ scavenging of DPPH free radical; bmEq uric acid = unit of antioxidant capacity for copper reduction; CTBARS (thiobarbituric acid-reacting substances) in control samples were $71.14( \pm 1.03) \mathrm{nmol} / \mathrm{mg} \mathrm{LDL}$; ${ }^{\mathrm{d}} \mathrm{Compounds} \mathbf{4 - 6}$ and $\mathbf{1 0}$ in the same fraction tested before their identification; eThe concentration of $\mathrm{MeOH}$ extract was $184 \mathrm{mg} / \mathrm{ml}$; Ascorbic acid, chlorogenic acid and quercetin are reference compounds. Experiments were performed in triplicate; results are mean \pm S.D. 


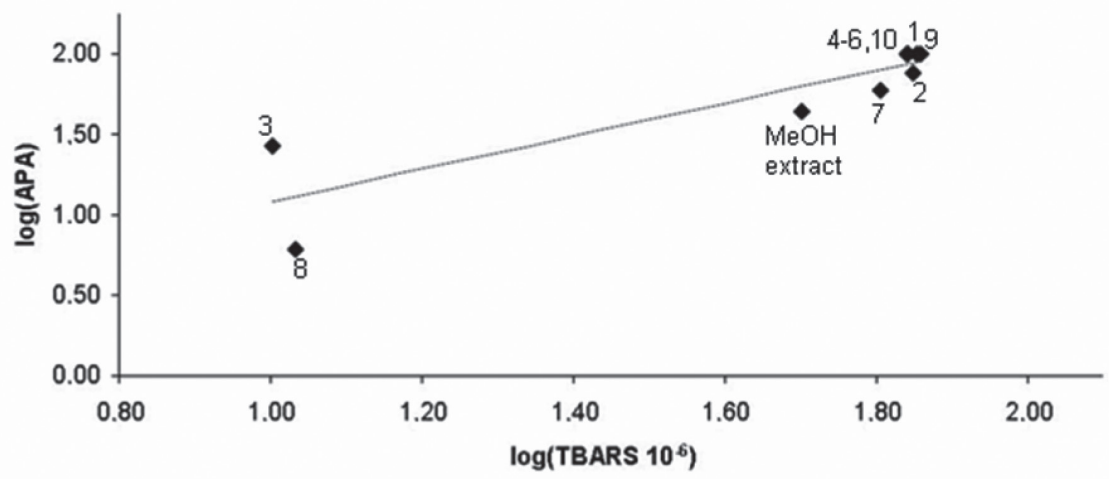

Figure 3. Comparison of antilipoperoxidant and antiplasmodial activities of compounds isolated from A. millefolium and its methanolic extract The antiplasmodial activity was determined in a chloroquine resistant strain of $P$. falciparum (W2).

\& Saliba, 2008). These results suggest that the presence of the 7-O-glycoside in the flavonoid moiety does not inhibit their antiplasmodial activity or that the aglycone becomes active after enzymatic hydrolysis of the glycoside bond.

Apigenin 4'-O-glucoside (7) and rutin (2) showed moderate activity against the both strains, while the other components were completely inactive.

\section{Antioxidant activity}

The antioxidant activity of the $\mathrm{MeOH}$ extract and its components were evaluated using different in vitro assays. The radical scavenging activity was evaluated by the $\mathrm{DPPH}$ test, the TAC by the copper reducing power assay and the anti-lipoperoxidant activity in LDL against $\mathrm{Cu}^{2+}$ insult by the TBARS assay. Ascorbic acid, chlorogenic acid and quercetin were used as reference compounds and the results are summarized in Table 3. Noticeably, for TAC, ascorbic acid did not exhibit significant differences between $10^{-5}$ and $10^{-6}$ concentrations. We speculatively attribute this to a plateau effect at low concentrations associated with the method.

The $\mathrm{MeOH}$ extract, whose polyphenolic content determined by the Folin-Ciocalteau method was $281.7 \mathrm{mg} / \mathrm{g}$, exhibited significant activities in all the models used, comparable to those of the control antioxidants. Concerning pure compounds, on the whole they displayed a rather high degree of activities. In particular rutin (2), chlorogenic acid (1) and its derivatives 4, 5, 6 and 10 (in the same fraction not further separated because of its low amount), and the apigenin derivatives 7 and $\mathbf{8}$ showed values similar to those of the reference standards, both in terms of scavenging ability (DPPH) and TAC.

The results from the TBARS assay showed that, among the compounds isolated, only $\mathbf{3}$ and $\mathbf{8}$ displayed an activity somewhat comparable to that of chlorogenic acid, even at the lowest concentration tested $(1 \mu \mathrm{M})$; all the other compounds were able to inhibit the TBARS formation only at the highest concentration tested $(10 \mu \mathrm{M})$.

\section{Statistics}

The correlation and multivariate regression analyses carried out on the antiplasmodial and antioxidant data of compounds $\mathbf{1 - 1 0}$ at $1 \mu \mathrm{M}$ concentration evidenced a significant correlation (Fig. 3) between their activity against TBARS formation and growth inhibition of the CQ re- sistant strain of P. falciparum $\left(\mathrm{R}_{\text {Spearman }}=0.786, P<0.005\right.$; regression: beta $_{\mathrm{TBARS}}=0.776, P<0.01$ ), suggesting that the antilipoperoxidant compounds were the same as those responsible for the inhibition of the parasite. As shown in Fig. 3, this correlation was mainly due to compounds $\mathbf{3}$ and $\mathbf{8}$ in both tests suggesting luteolin 7-O-glucoside (3) and apigenin 7-O-glucoside (8) as the components putatively responsible for both the antilipoperoxidant and antiplasmodial activities of the $\mathrm{MeOH}$ extract. To some extent, these results are in accordance with those of other studies (Kirmizibekmez et al., 2004; Tasdemir, 2006; Tasdemir et al., 2006) that reported luteolin 7-O-glucoside (3) as an inhibitor of $P$. falciparum growth. Most importantly, they provided evidence that inhibition of enzymes involved in the plasmodial type II fatty acid biosynthesis is a potential biochemical target for the in vitro inhibitory activity of flavonoids against the parasite. It is interesting to observe that the isomeric forms of $\mathbf{3}$ and 8 , in which glycosylation occurs at the 4'-O-position (compounds 7 and 9), are much less active in both tests, confirming that the availability of ring $\mathrm{B}$ phenol groups is an important factor for the definition of the structureactivity relationships of these compounds.

\section{CONCLUSIONS}

The results of this work contribute to the definition of the phytochemical profile of the $\mathrm{MeOH}$ extract of $A$. millefolium. Evaluation of the antioxidant and antiplasmodial activities of the isolated pure compounds suggests that flavonoid glycosides $\mathbf{3}$ and $\mathbf{8}$ are the main components responsible for both investigated activities and, to the best of our knowledge, antiplasmodial activity of apigenin 7-O-glucoside is reported here for the first time, as well as the correlation between the antioxidant power and the antiplasmodial activity of the isolated compounds.

\section{Acknowledgements}

The authors are grateful to Dr. G. Rotti for plant identification. This work was supported by MIUR grant PRIN 2004038183/004.

\section{REFERENCES}

Benedek B, Gjoncaj N, Saukel J, Kopp B (2007) Distribution of phenolic compounds in Middle European taxa of the Achillea millefolium L. aggregate. Chem Biodivers 4: 849-857. 
Glasl S, Mucaji P, Werner I, Presser A, Jurenitsch J (2002) Sesquiterpenes and flavonoid aglycones from a Hungarian taxon of the Achillea millefolium group. Z Naturforsch 57c: 976-982.

Guédon D, Abbe P, Lamaison JL (1993) Leaf and flower head flavonoids of Achillea millefolium L. subspecies. Biochem Syst Ecol 21: 607-611.

Innocenti G, Vegeto E, Dall'Acqua S, Ciana P, Giorgetti M, Agradi E, Sozzi A, Fico G, Tomè F (2007) In vitro estrogenic activity of Achillea millefolium L. Phytomedicine 14: 147-152.

Kaur K, Jain M, Kaur T, Jain R (2009) Antimalarials from nature. Bioorg Med Chem 17: 3229-3256.

Kirmizibekmez H, Çalis I, Perozzo R, Brun R, Dönmez AA, Linden A, Rüedi P, Tasdemir D (2004) Inhibiting activities of secondary metabolites of Pblomis brunneogaleata against parasitic protozoa and plasmodial enoyl-ACP reductase, a crucial enzyme in fatty acid biosynthesis. Planta Med 70: 711-717.

Kokkini S, Kleftoyanni V, Hanlidou E, Karousou R (2004) The herbal market of Thessaloniki (N Greece) and its relation to the ethnobotanical tradition. J Ethnopharmacol 91: 281-299.

Konyalioglu S, Karamenderes C (2005) The protective effects of Achillea $\mathrm{L}$. species native in Turkey against $\mathrm{H}_{2} \mathrm{O}_{2}$-induced oxidative damage in human erythrocytes and leucocytes. I Ethnopharmacol 102: 221-227.

Lehane AM, Saliba KJ (2008) Common dietary flavonoids inhibit the growth of the intraerythrocytic malaria parasite. BMC Res Notes 1: grow 26.

Makler MT, Ries JM, Williams JA, Bancroft JE, Piper RC, Gibbins BL, Hinrichs DJ (1993) Parasite lactate dehydrogenase as an assay for Plasmodium falciparum drug sensitivity. Am J Trop Med Hyg 48: 739-741.

Miraldi E, Ferri S, Mostaghimi V (2001) Botanical drugs and preparations in the traditional medicine of West Azerbaijan (Iran). J Ethnopharmacol 75: 77-87.

Murnigsih T, Matsuura SH, Takahashi K, Yamasaki M, Yamato O, Maede Y, Katakura K, Suzuki M, Kobayashi S, Yoshihara C, Yoshihara T (2005) Evaluation of the inhibitory activities of the extracts of indonesian traditional medicinal plants against Plasmodium falciparum and Babesia gibsoni. J Vet Med Sci 67: 829-831.

Passalacqua NG, Guarrera PM, De Fine G (2007) Contribution to the knowledge of the folk plant medicine in Calabria region (Southern Italy). Fitoterapia 78: 52-68.
Pieroni A, Quave CL (2005) Traditional pharmacopoeias and medicines among Albanians and Italians in southern Italy: a comparison. $J$ Ethnopharmacol 101: 258-270.

Pignatti S (1982) Flora d'Italia 3: 77-85. Edagricole, Bologna.

Saxena S, Pant N, Jain DC, Bhakuni RS (2003) Antimalarial agents from plant sources. Curr Sci 85: 1314-1329.

Schwikkard S, van Heerden FR (2002) Antimalarial activity of plant metabolites. Nat Prod Rep 19: 675-692.

Sharma PK, Chauhan NS, Lal B (2004) Observations on the traditional phytotherapy among the inhabitants of Parvati valley in western Himalaya, India. J Ethnopharmacol 92: 167-176.

Stojanović G, Radulović N, Hashimoto T, Palić R (2005) In vitro antimicrobial activity of extracts of four Achillea species: the composition of Achillea clavennae L. (Asteraceae) extract. J Ethnopharmacol 101: 185-190.

Tasdemir D (2006) Type II fatty acid biosynthesis, a new approach in antimalarial natural product discovery. Phytochem Rev 5: 99-108.

Tasdemir D, Lack G, Brun R, Rüedi P, Scapozza L, Perozzo R (2006) Inhibition of Plasmodium falciparum fatty acid biosynthesis: evaluation of FabG, FabZ, and FabI as drugs targets for flavonoids. $J$ Med Chem 49: 3345-3353.

Teng R, Xie H, Li HZ, Liu X, Wang D, Yang C (2002) Two new acylated flavonoid glycosides from Morina nepalensis var. alba Hand.Mazz. Magn Reson Chem 40: 415-420.

Trager W, Jensen JB (1976) Human malaria parasites in continuous culture. Science 193: 673-675.

Vitalini S, Grande S, Visioli F, Agradi E, Fico G, Tomè F (2006) Antioxidant activity of wild plants collected in Valsesia, an alpine region of northern Italy. Phytother Res 20: 576-580.

Vitalini S, Tomè F, Fico G (2009) Traditional uses of medicinal plants in Valvestino (Italy). J Ethnopharmacol 12: 106-116.

Yaeesh S, Jamal Q, Khan AU, Gilani AH (2006) Studies on hepatoprotective, antispasmodic and calcium antagonist activities of the aqueous-methanol extract of Achillea millefolium. Phytother Res 20: 546-551.

Wang Y, Liu B (2007) Preparative isolation and purification of dicaffeoylquinic acids from the Ainsliaea fragrans champ by high-speed counter-current chromatography. Phytochem Anal 18: 436-440. 